\title{
الرضا الوظيفي وتأثيره على الأبناء
}

\author{
أعراد \\ الباحث/ حسين خضير محمد مشهدي
}

إبراف

أ ـ د/ حسيز محمد سعد الدين الحسيني

أستاذ علم النفس

بكليتّالآداب - جامعتَ المنصورة

المجلت العلميت لكليت رياض الأطفال ـجامعت المنصورة

المجلد الخامس ـ العدد الأول

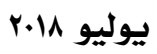




\section{الرضا الوظيفي وتأثيره على الأبناء}

أر حسين خضير محمد مشهدي

يعتبر موضوع الرضـا الوظيفي مــن الموضـــوعات الهامـــة و المفــاهيم

الأساسية والتي كتب فيها الباحثون في علم النفس و الإدارة الــشيء الكثيــر و لا غر ابة في ذللك لان الإنسان يمضي وقتاً و لا باس به من عمره في العمل و العمل بالنسبة لي فرد في المجتمع يعتبر جز اء أو مظهر أ من شخصية ، فالعمل بعطي

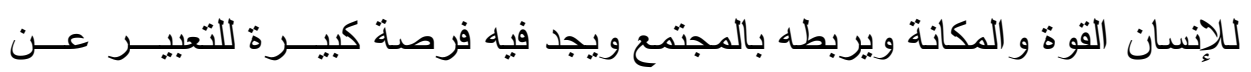
ميوله و استعد اده وطمو حاته وقدر اته ور غباته.

ولعل من أسباب كثرة البحوث و الدراسات في موضوع الرضا الوظيفي ، هو الاعتقاد السائد انه كلما زادت درجة الرضا الوظيفي ، فان ذلك يوثز إيجابــاً على إنتاجية الفرد كماً ونو عاً، ولذلك فان الاهتمام بالرضا الوظيفي يعتبر أهــراً محوريا إذا ما أردنا النهوض بمستوى العمل من حيت الكفاءة و الإنتاجيــة، مــع العلم بان الرضـا الوظيفي هو وسيلة وليس هدفا في حد ذاته لا انه يعدــل علــى

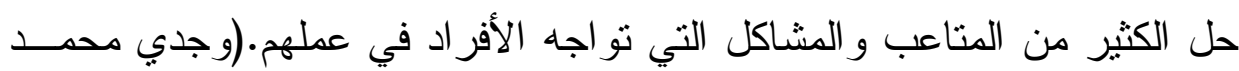
(or: : r... \&。

ومن الحقائق العلمية أن عطاء الفرد وكفاءته المهنية دليـلـل علـى مــدى رضاه عن عمله ويزداد هذا العطاء بمقدار ما يوفره العمل له من إثباع لحاجاته و دو افعه وهو يمنل مؤشر هام على فعالية التنظيم.

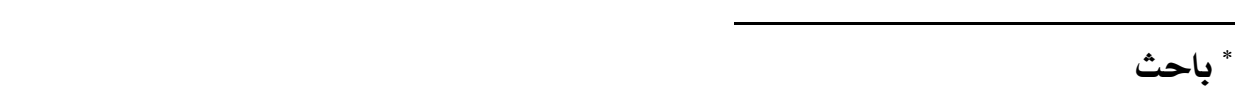


وقد بدأ موضوع الرضا عن العمل" الرضا الوظيفي لا أول مرة في مجال

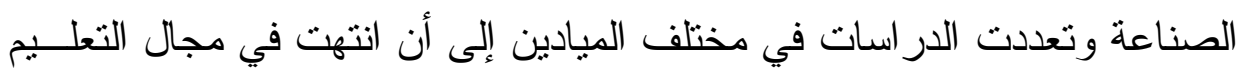

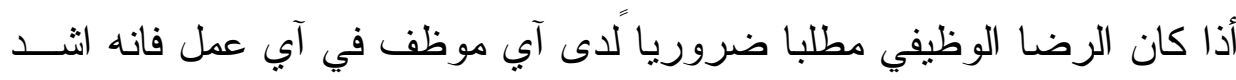

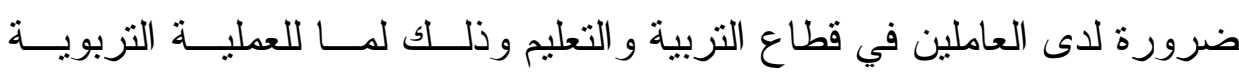

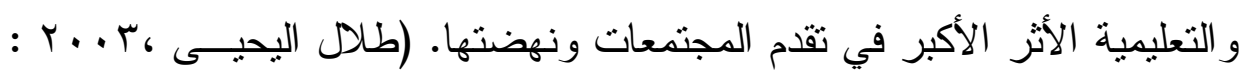

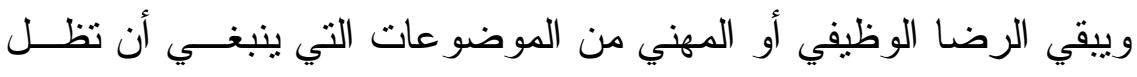

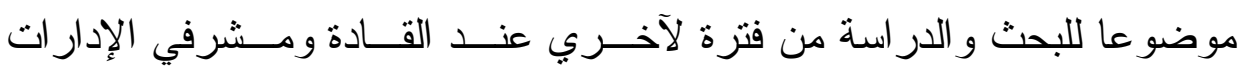

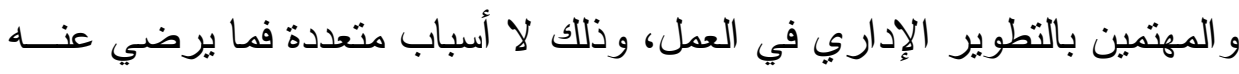

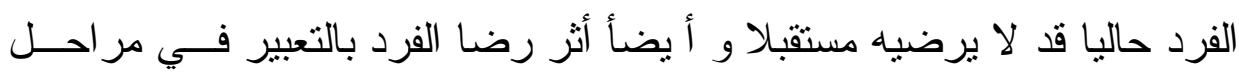

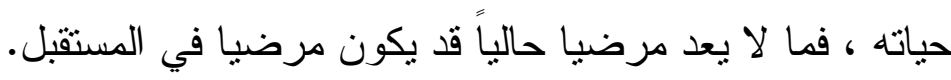

\section{* - مفهوم الرضا الوظيفي : - م}

إن مفهوم الرضا الوظيفي متعد د الجو انب و الأبعاد ويتأثر بعو امل يعـود

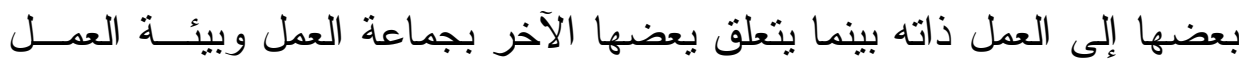

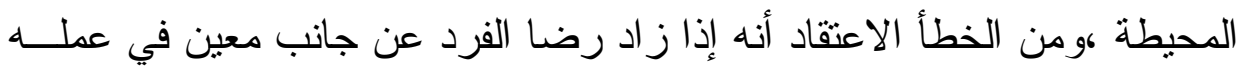

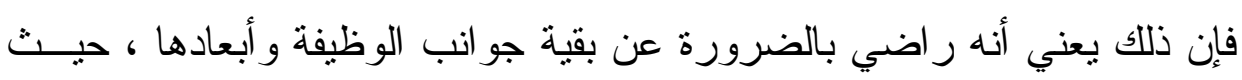

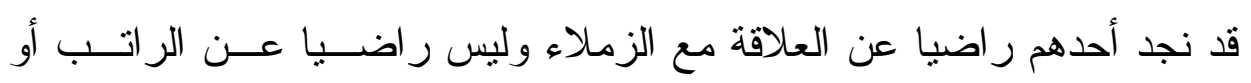

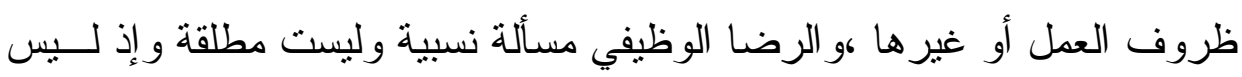

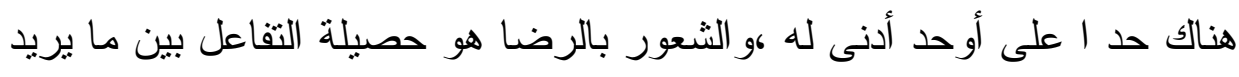

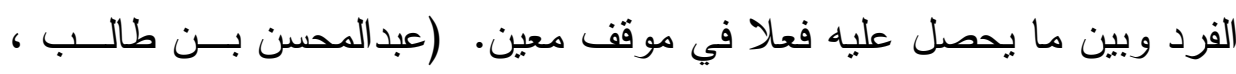
(ro: r... 
ويعتبر مفهوم الرضا الوظيفي من المفاهيم التي اكتسبت أهمية خاصة في

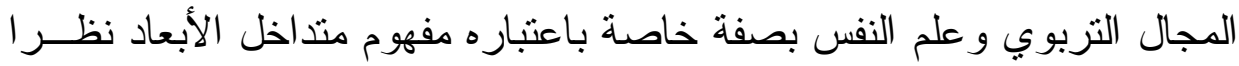
لتعلقه بمشـاعر الفرد تجاه عمله وميوله وتوقعاته مقابل ما يقدمه من عمل وبــين ما يحصل عليه بالفعل وقد اختلف العلماء في تحديد الأهمية النسبية لكل بعد من

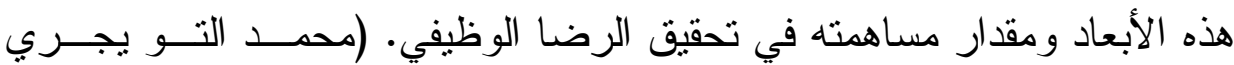

$(\varepsilon \wedge \cdot:$ : 1990。

لا يوجد هناك أتفاق بين الباحثين حول مفهوم محدد للرضـــا الــوظيفي ،

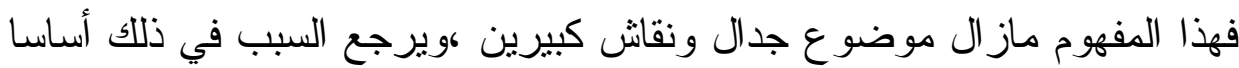

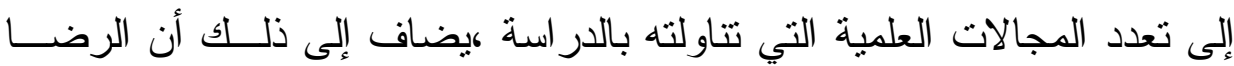

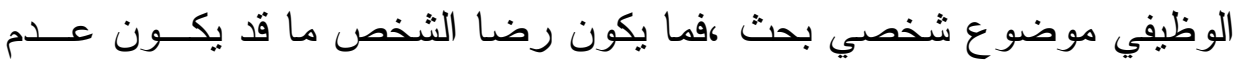
رضا شخص آخر.

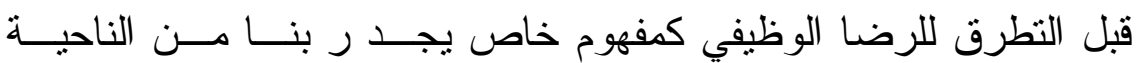

$$
\begin{aligned}
& \text { المنهجية أن نتطرف أو لا للرضا كففهوم عام. } \\
& \text { أولا : تعريف الرضا كمفهوم عام : }
\end{aligned}
$$

في اللفة: هو ضد السخط وارتضاه يعني رآه له أهلا ورضي عنه ،أحبه

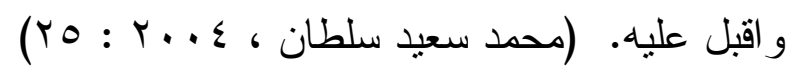

في الاصطلاح: فقد عرفه أوارد شيت بأنه الحالة العقلية للإنـسان التـي

\begin{tabular}{|c|c|}
\hline 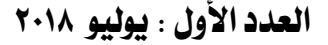 & rAV \\
\hline
\end{tabular}

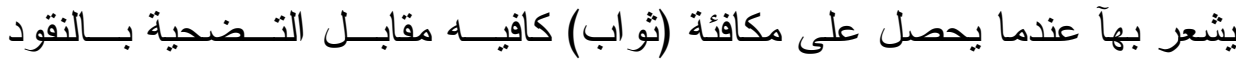

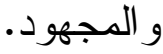




\section{ثانيا : تعريف الرضا الوظيفي}

قد يكون من الصعب إيجاد تعريف متفق عليــهـهــــين البــاحثين للرضـــا الوظيفي ،نظر ا لكونه ظاهرة نفسية مرنبطة بالإنسان الذي يتصف بأنه مخلــوق

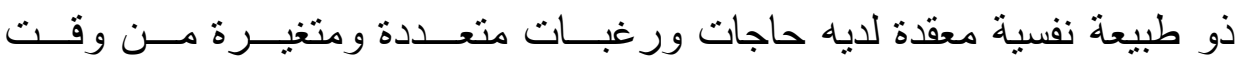

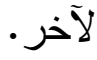

لذللك اختلف علماء النفس في وجهات النظر لتعريف الرضـــا الــوظيفي فالبعض بركز على جانب المشاعر والأحاسيس الثخصية متل الثعور بالسعادة و الحب اتجاه العمل ويركز البعض الآخر على درجة تقبل الفرد لعمله ومنهم من العن العنائ

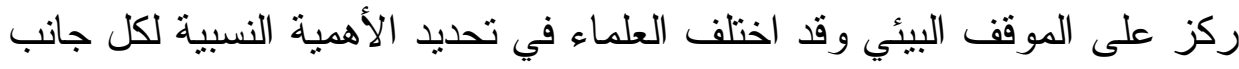

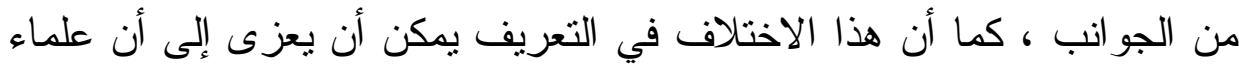

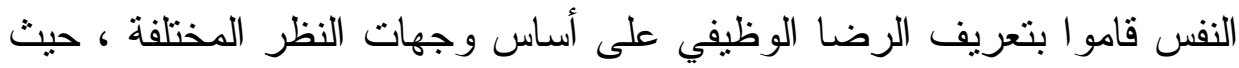

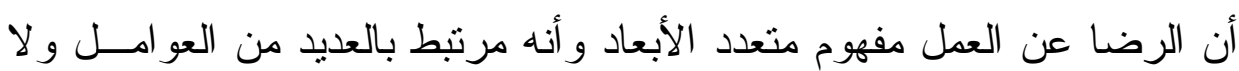

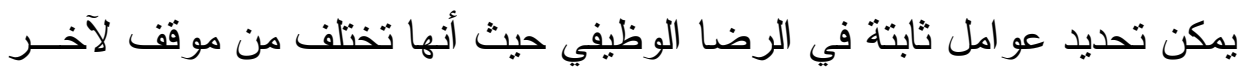

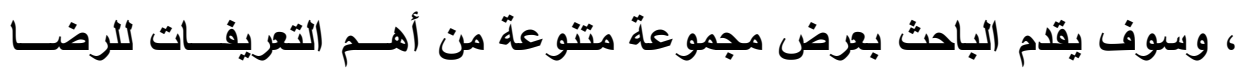
الوظيفي في التراث السيكولوجي على النحو التالي :

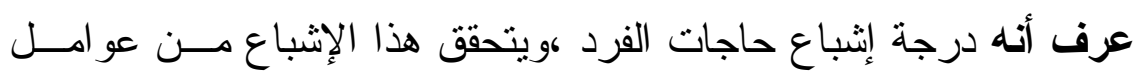

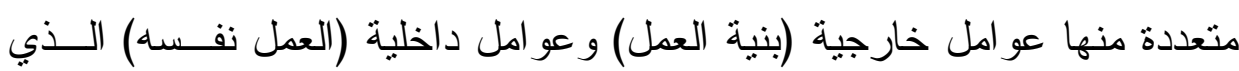

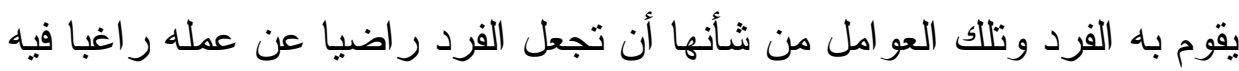

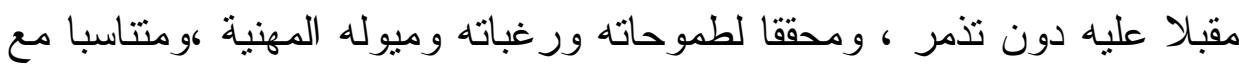
ما يريده الفرد من عمله وبين ما يحصل عليه في الواقع أو يفوق توقعاته. (عويد وايد

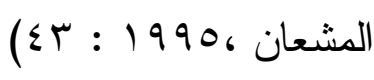


عرف الرضـا عن المهنة هو حالــة وجدانيــة شــعورية ســارة يميزهــــا

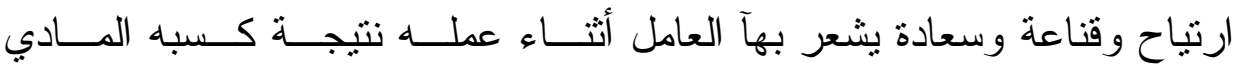
وتحقيق المكانة الاجتماعية و الثـعور بالانتماء المهنــي وتحقيـق الـــات و الأداء الوظيفي و الإنجاز و الطموح فهو حصيلة العو امل المتعلقة بالعمل و التـي تجعـلـ الفرد محبا له مقبلا عليه في بدء يومه دون أي غضاضة.(حامد زهران ، 1990

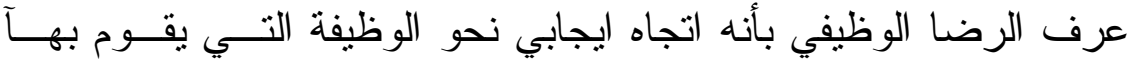

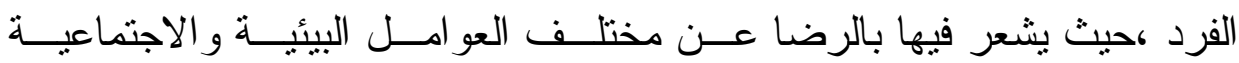
و الاقتصادية و الإدارية و الفنية المتعلقة بالوظيفة. (خالد عيد الصماني ، 9 . .. :

وأن الرضا عن المهنة بأنه حالة ذهنية تـشمل جميـع المـشـاعر التـي يحددها مدى إدر الك الفرد لمهنته و التي تتعلق بالاحتياجات التي ينبخــي تلبيتهــا.

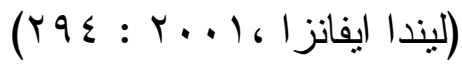
ويعرف الرضا عن المهنة أنه يعكس مستوى الاتـز ان فـــي المـشـاعر الإيجابية و السلبية نحو العمل بمختلف إبعاده كالر اتب وظروف العمل و العلاقــة

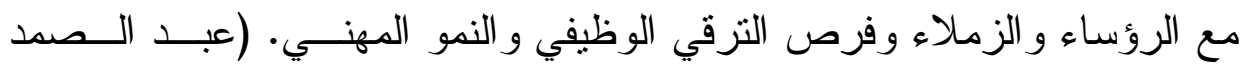

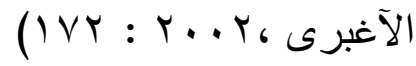

تعريف الباحث للرضا الوظيفي: هو الثعور الايجابي الذي يتكون لــدى الفرد نحو عمله و اتجاه ظروفه وحو افزه المادية و المعنوية و العلاقات التي يبنيها داخل جو العمل ومدى ارتياحه وقناعته بما يقوم به من مهام و أعمال وما يمتلكه من صلاحيات مما يؤدي إلي زيادة الإنتاجية لديه. 
التعريف الإجرائي للرضا الوظيفي: هو الدرجة الكلية التي يحصل عليهــا

المعلمين و المعلمات من خلال الإجابة على كل فقرة من فقرات مقياس الرضــــا

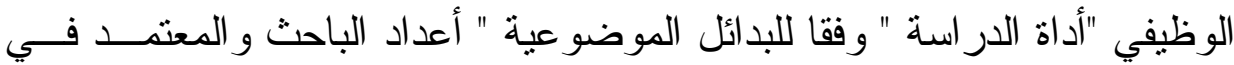

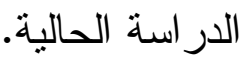

يتضتح من خلال العرض السابق لبعض تعريفات الرضـا الـــوظيفي أنـــه

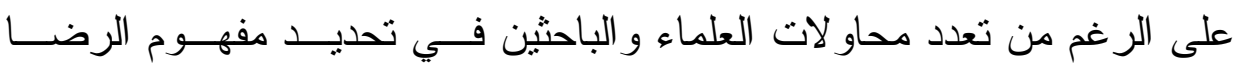
الوظيفي تحديدا دقيقا ،إلا أن هذه التعريفات ركزت في معظمها على الجوانــب التي تسبب الرضا أو عدم الرضا عن العمل يتحقق من عدة عو امل منها : ا - ما يتصل بالفرد ذاته (عو امل نفسية تشمل تقدير الفرد للعمل، وقـدر ات العامل وسماته الثخصية و إثنباع حاجات الفرد و الإحــساس الإيجــابي نحو العمل).

r - ما يتصل بالعمل أو المؤسسة (العو امل الوظيفية من الخبــرات الــسارة و غير السارة المرتبطة بالعمل جماعة العمل التي يعمل معها ورؤســائه الذين يخضع لإشر افهم ،حول محيط العمل من التوتر والقلق). r - ما يتصل بالبيئة المحيطة بالعمل (العو امل الخارجية أو الأوضـاع البيئيــة المحيطة بالعمل وما يتصل به.

$$
\text { أنـــواع الـــرضـــا: }
$$

بما أن الرضـا الوظيفي هو ذلك الثـور بالارنياح النفسي في بيئة العدـلـ

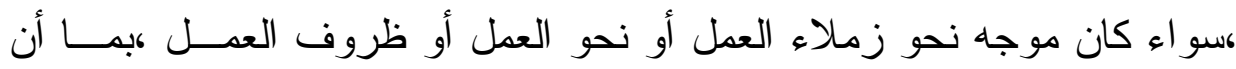


هنالك اختلافات في درجة الرضـا الوظيفي خلال الحياة الوظيفية ،فإنـــه يمكنـــا تقسيم الرضا إلى عدة أقسام وفقا لاعتبار ات مهنية كالتالي:

أنواع الرضا الوظيفي باعتباره شمولية

أ- - الرضـا الوظيفي الداخلي: يتعلق بالجو انب (الذاتية) للمعلمين و المعلمــات

مثل الاعتر اف و التقدير و القبول و الثتعور بالتمكن و الإنجاز و التعبيــر

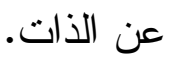

ب- الرضا الوظيفي الخارجي: يتعلق بالجو انب الخارجية (البيئية) للمعلين و المعلمات في محيط العمل مثل المدير ، زملاء العمل وطبيعــة ونمـــ

العمل.

ج- النمط الكلي العام كوهو محل الثعور بالرضـا الوظيفي تجــاه الإبعـاد الداخلية و الخار جية معاً.

\section{أنواع الرضا الوظيفي باعتبار زمنه}

أ- - الرضـا الوظيفي المتوقع ،ويشعر المعلمين و المعلمات بهذا النــوع مــن خلال عملية الأداء الوظيفي إذا كان منوقعا ما يبدله من جهد يناسب مع

$$
\text { هدف المهمة. }
$$

ب- الرضا الوظيفي الفعلي ،هذا النوع يحدث بعد مرحلة الرضـا الــوظيفي المتوقع ،عندما يحقق الهدف فيشعر حينها بالرضـا الــوظيفي. (نــــواف

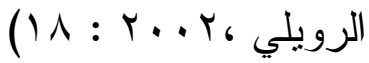

$$
\begin{aligned}
& \text { قـ بـاس الرضـــــــا الوظيفي: }
\end{aligned}
$$

بما أن الرضا الوظيفي يشمل مشاعر و أحاسيس غير محسوسة فإن القدرة على التعرف عليها و الوصول إليها يعتبر عملية ليست ســـلة ،ولقــد اسـتفادت 
مقاييس الرضا الوظيفي من التقدم الذي حدث في مجال علم النفس مــن حيــ أساليبه لدر اسة الثخصية و الاتجاهات وغير ها من الجو انــب النفـسية ،و هنـــاك طرق ومقاييس مختلفة لقياس مستوى الرضـا الوظيفي وتحديــــــــــابه حيـــ تختلف في مدى فاعليتها على ما توفره تللك المقــاييس مــن الدقـــة و الـشـمول للبيانات.

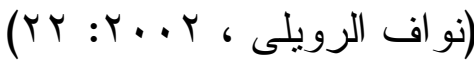

\section{أهمية الرضا الوظيفي :}

يعتبر العنصر البشري من أهم العناصر المؤثرة في إنتاجية العمـلـل فهـــ دعامة الإنتاج وتحدد مهارته مدى كفاءته، وقد تترتب علــى إهمــال العنــصر البشري في بعض المجتمعات و المؤسسات و أن تختلف وتقصت إنتاجيتها و هــذا مما يدعو إلى در اسة الرضا الوظيفي لما له من أهمية تطبيقية و عملية. ويعد الرضنا الوظيفي من أهم مقومات التو افق الوظيفي السليم ، لذا فــانن من أهم الخدمات النفسية في هذا الصدد خدمات التوجيه والانتفاء المهني بحيث يحققون أفضل درجة ممكنة من التو افق مع ظروف عملهم ومنطلبات الأداء فيه. تأتي أهمية الرضا عن المهنة كونه يشكل أحد الأسباب أو الدوافع المهمة للأداء المتميز الذي يمكن أن يؤدوه المعلمون و المعلمات حيث أن أساس التو افق النفسي و الاجتماعي لهم مؤشر النجاحهم في مختلف جو انب حياتهم و فاعلية أداء

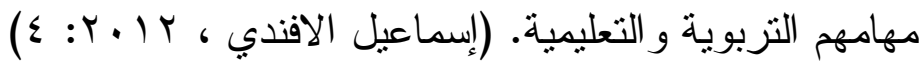

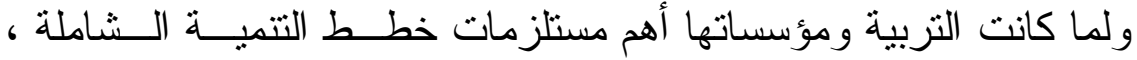
حيث أنها مسوله عن التخطيط لاستخدام الثروة البشرية وكيفية تتميتها واستمر ار 
نموها ورفع كفاءاتها ، فان مهنة التعليم تعتبر من أهم المهن التي تـساهم فـي

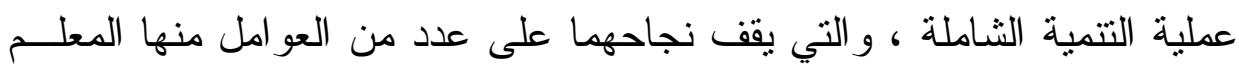
الذي يعد جوهر العملية التزبوية و التعليمية ،فمستوى أدائه للمهمات و المستويات

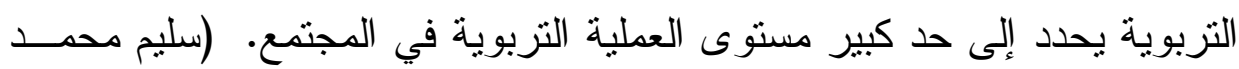

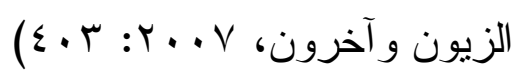

و لا شكك أن در اسة الرضا الوظيفي للمعلمين و المعلمات هي عملية نقــويم

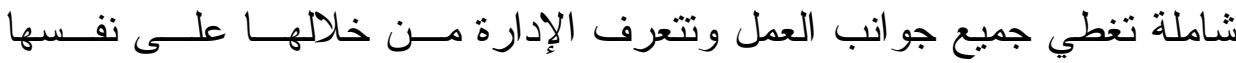

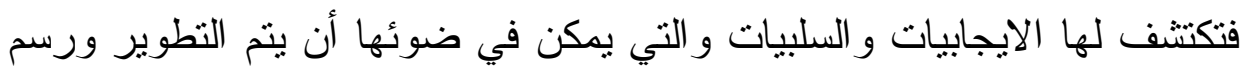
السياسات المسنقلية للإدارة ، و إذا كانت الدول المتقدمة قد اهتمت وما تز ال تهتم

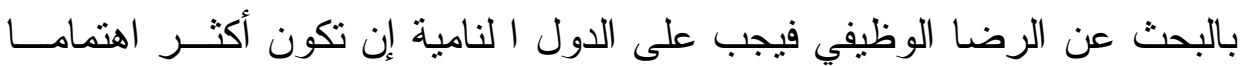

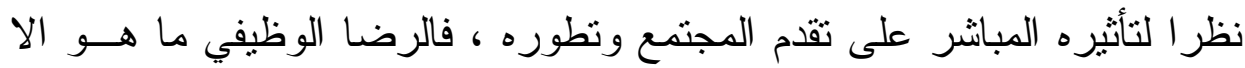
تجميع للظروف النفسية و الفسيولوجية و البيئية و الني تحيط علاقة المعلم بزملائه

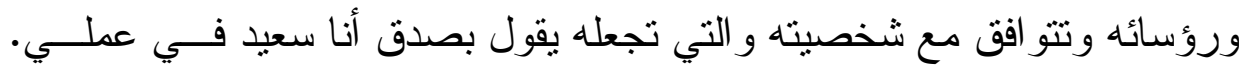

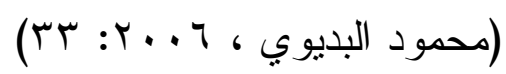

فتظهر أهمية الرضا الوظيفي للمعلمين في مدى تأثثره في تحديد درجـة كفاءة الخدمات التي تسعى المؤسسة النعليمية إلى تحقيقها وحجم الإنتاج ونوعية.

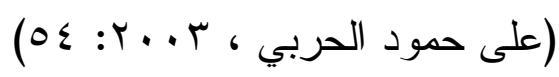

ذلك لدور المعلم الأساسي في بناء المجتمع وتأسيس الأجيال، لهــذا فــإن رضاه عن عمله من الجو انب المهمة باعتباره احد الدعائم الأساسية لعملية التعليم

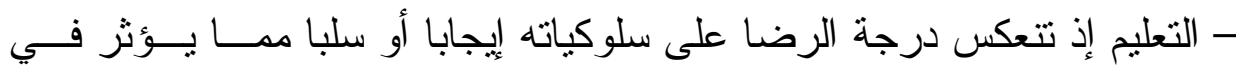


تشكيل اتجاهات الطلبة وأساليب تفكير هم وقيمهم و عاداتهم وقدر اتهم المختلفة إلى

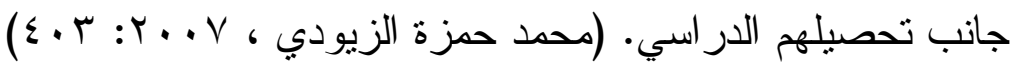

ويعد رضا المعلم عن وظيفته من الأهمية الضرورية إذا أردنـــــايــــة

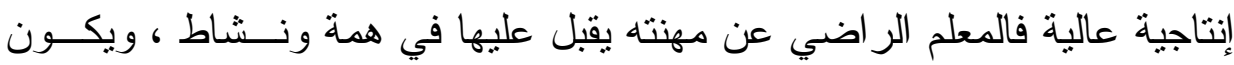
سعيدا بهآ ، فما يزيد من كفايته الإنتاجية ، أما عدم الرضا عن المهنة فينتج عنه سوء تكيف ، فالفرد غير الر اضي عن وظيفته يكون غير منو ازن انفعاليا ويظهر الكثير من مظاهر الضجر و الملل ، ومن الصعب عليه إن يتكيف مع المهنة.

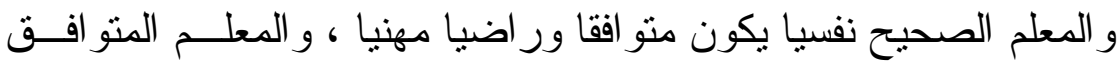
مهنيا هو الذي يتو افق مع بيئة المدرسة وظروفها ويعتز بوظيفته ويقيم علاقــات

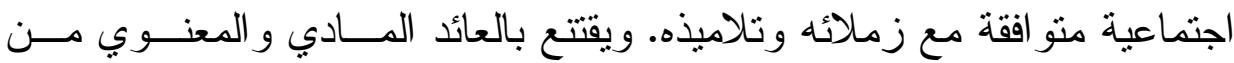
عمله.

إن المعلم الذي لا يحقق الرضـا النفسي عن طريق العمل يحسـاول تحقيــق

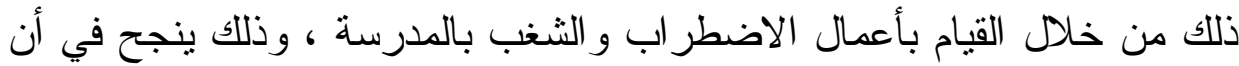

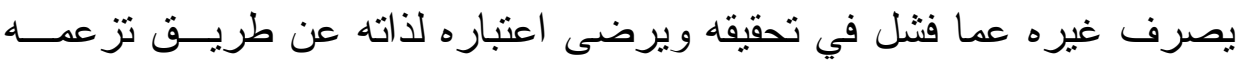
لهذه الحركات ، لهذا ينبغي أن تقوم القيادات المدرسية بدر اسة الأسباب الحقبقيــة فئسة

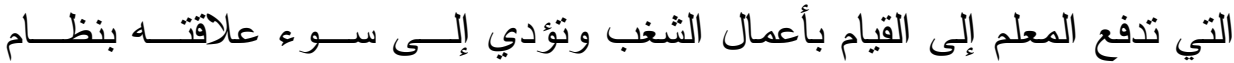

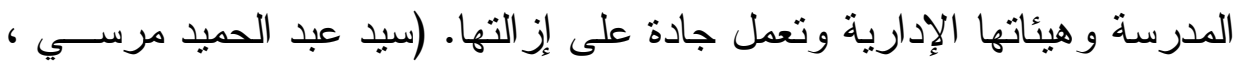
(10:1910

و إن للرضا عن المهنة أهمية كبيرة حيث يعتبر من أهم مؤشرات الصحة

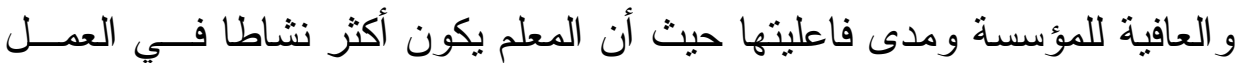
لأنه يتتاول مشاعره إز اء المهنة التي يؤديها و البيئة المحيطة بهآ. 
حيث توجد العليد من الأسباب التي تلعو إلى الاهتـــام بالرضــا عـن

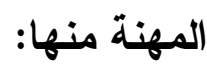

1- للرضـا عن المهنة أهمية على الصحة النفسية حيث أن الحالــة النفـسية

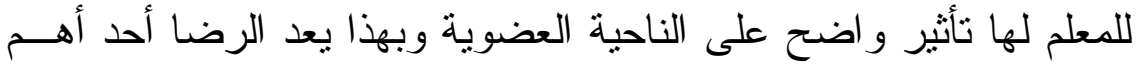
مسبيات التو ازن النفسي على الصحة العضوية. Y- إسهام الرضا عن المهنة في التأثثر على كل سلوكيات المعلم. r- ارتفاع درجة الرضـا عن المهنة يؤدي إلى ارتفاع درجة الطمــوح لــدى المعلم في المؤسسات المختلفة. ع - ارتفاع مستوى الرضـا عن المهنة يؤدي إلى انخفاض نسبة غياب المعلــــ و العاملين في المؤسسات المختلفة.

ه- إن المعلم ذو الرضا المرتفع عن المهنة تكون أقل عرضة لمشاكل العــلـ و أكثر رضا عن الحياة بصفة عامة.

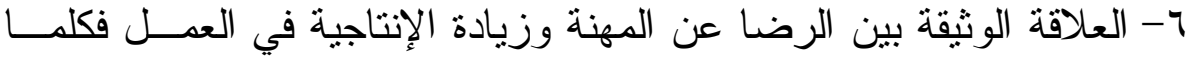
كان هنالك درجة عالية من الرضا عن المهنة أدى ذلك إلى زيادة الإنتاج.

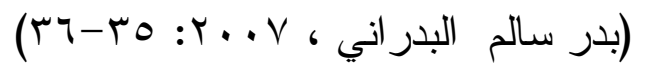

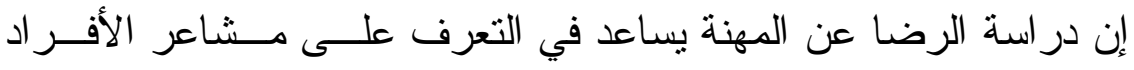

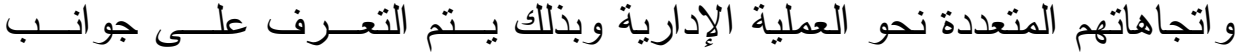
القصور و تلافيها ويتم أيضا معرفة المشكلات التي تهم المـشرفين الإداريــين

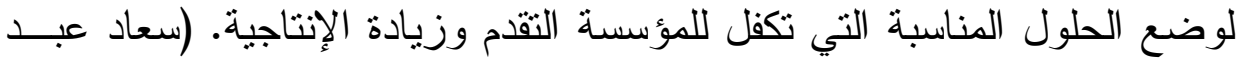

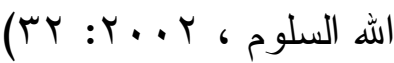


ويعتبر الرضا عن المهنة أحد العناصــر الهامــة فــي تحقيـق الأمــن

و الاستقر ار النفسي و الفكري و الوظيفي للمعلم بمختلف المؤسسات حيث بــدفعهم طو عا إلى زيادة الإنتاج وهو في النهايــة مـــا تتـشده المؤسـسـة. (عبدالــصمد

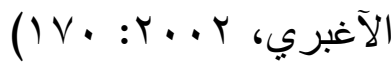

ويعد الرضا الوظيفي أو المهني من الموضوعات التي ينبغـــي أن تظـلـل

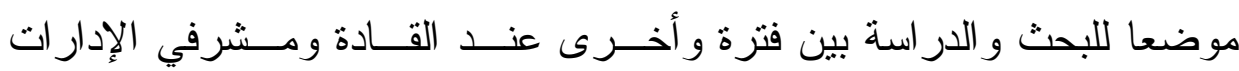

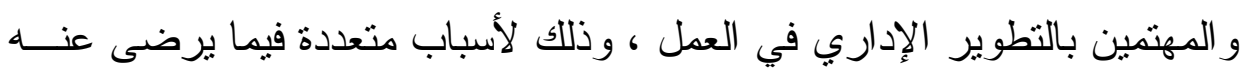

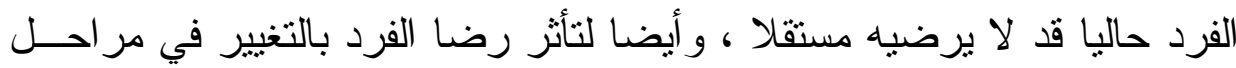
حياته فما لا يعد مرضيا حاليا قد يكون مرضيا في المستقبل. (محمود البديوي ، (ro: : : T T أهم مظاهر الرضا الوظيفي: يمكن أن نستدل على الرضا عن المهنة بالنسبة للمعلم عند أدائه لعمله من خلال بعض المظاهر التي سوف تتصل بسلوكه في العمل هي : ا - الإنتاجية المرتفعة.

إن العلاقات الإنسانية الجيدة و الفعالة تعني دائما إنتاجية مرتفعة من جانب المعلم و هذه الكفاءة الإنتاجية ترجع إلى إحــساس المعلــم بالانتمــاء للمؤسـسـة وحرصه على مصلحتها و أيضا إلى إحساسه بقيمة ما يقوم بـه من عمل وشعوره بـهاه بأن إدارة المؤسسة تعمل دائما على حل مشاكلهم ومشاكل العمل لزيادة الإنتــاج وتحقيق جودته. (فاروق فليه ، السيد عبد المجيد ، 0. . ب: 9 (1)

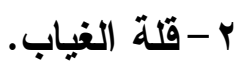




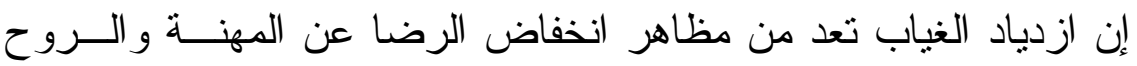

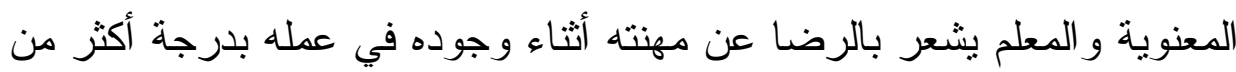

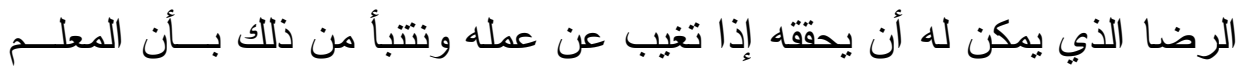

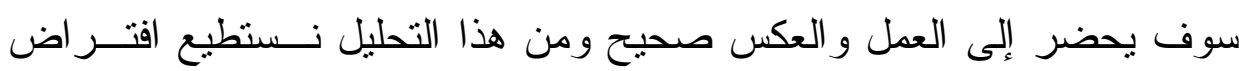

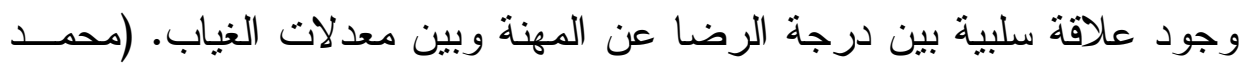

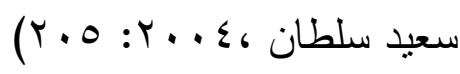

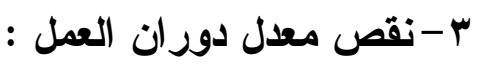

دوران العمل هو انتقال المعلم من عمل متخصص إلى آخر حيث أن هذه

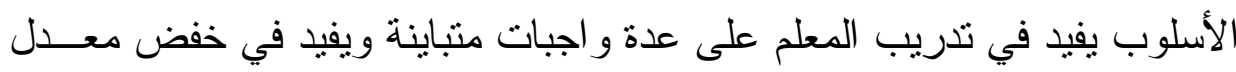

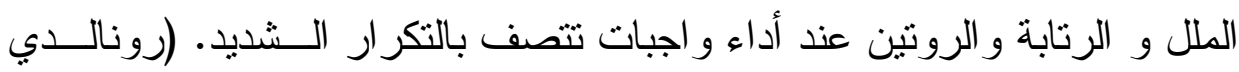

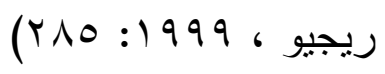

و إنه كلما زاد رضا المعلم عن مهنته ز اد الدافع لديه على البقاء في هــــه

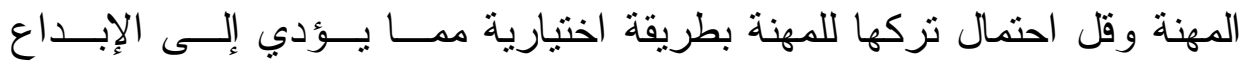

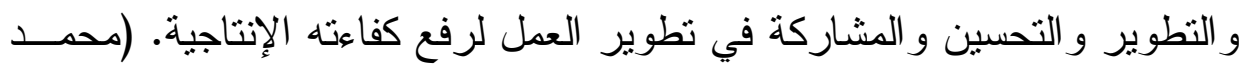

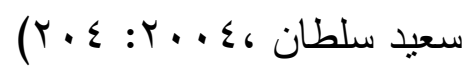
ع - انخفاض درجة مقاومة التغير.

يعد انخفاض مقاومة التغيير مظهر من مظاهر الرضا عن المهنة حيــث

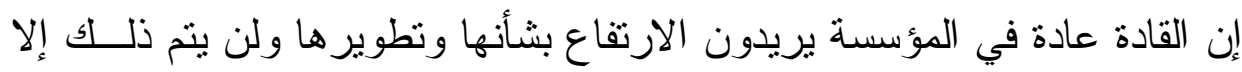

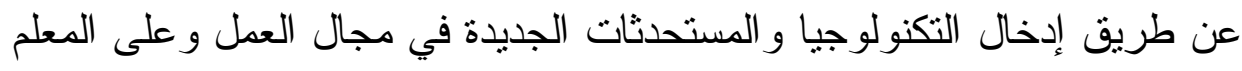

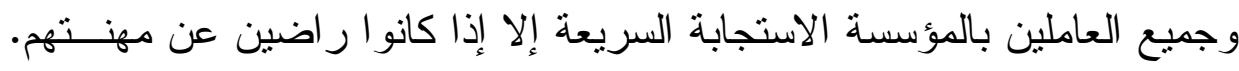

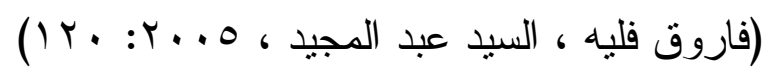




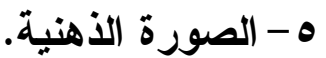

إن الصورة الذهنية الايجابية للمؤسسة ونوع العـــل بهـآ لــدى جميـع

العاملين فيها بوجه عام و المعلم بوجه خاص تعد مؤشر ا هاما للرضـا عن المهنــة

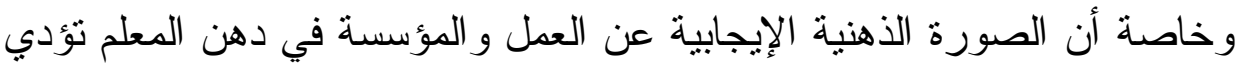

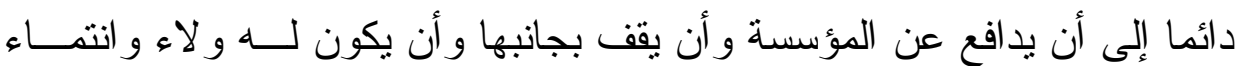

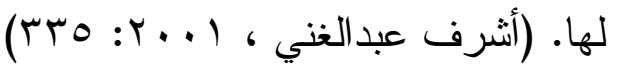

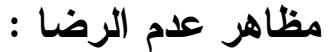

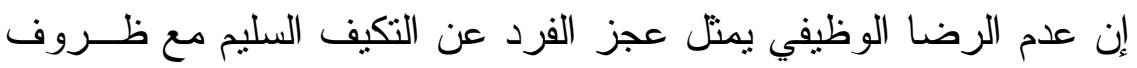

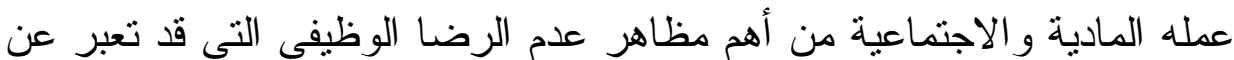

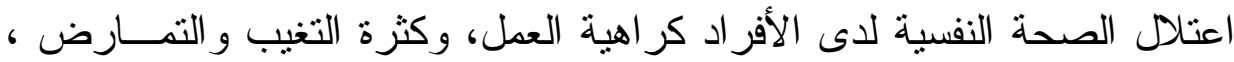
و إساءة استخدام المو اد و الأدو ات ،و انخفاض مستوى الإنتاجية، و الكسل و الخمول

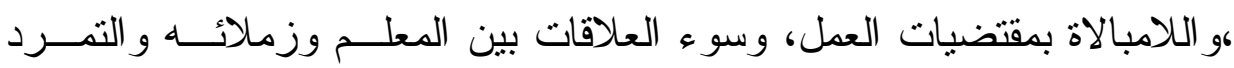

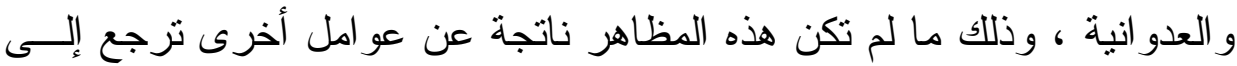

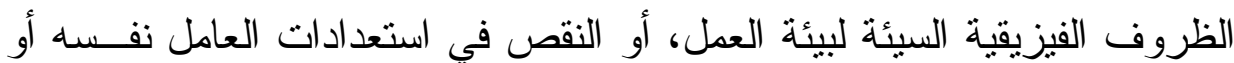

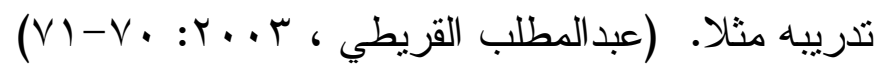

ومن العوامل التي تؤدي إلى نقص الرضــــا الــوظيفي التـوتر النفـسـي

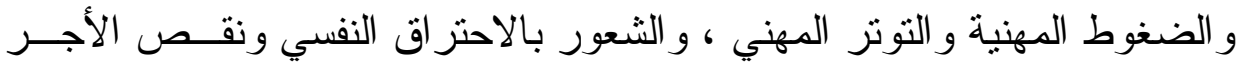
وتباطؤ الترقي و عدم الرضا عن الإثشر اف، وسوء ظروف العمل، كذلك فإن من مصاحبات نقص الرضا المهني. القلق و الثُعور بعـدم الجــدوى و العـصابية

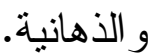




\section{من أبرز مظاهر عدم الرضا الوظيفي ما يلي:

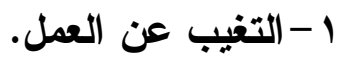

وهو تخلف الفرد عن الحضور إلى العمل في ظروف كــان بإمكانسـهـ أن يتحكم فيها ، ولذلك يعتبر من أخطر المشكلات التي تو اجه المؤسسات لما له من

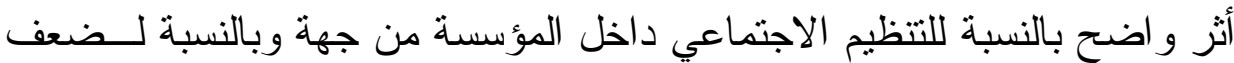

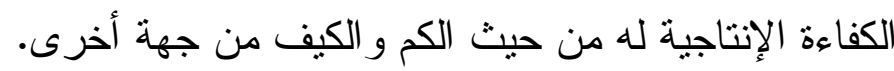
ب-ترك العمل الاختياري.

ويشير إلى الاستقالة من العمل بالتعليم ، مما يكلف الددارس تكلفة عاليــة

يتمتل بعضها في تكلفة التدريب وتكلفة تعيين معلمين جدد ، وكلما ارتقينـا فـي

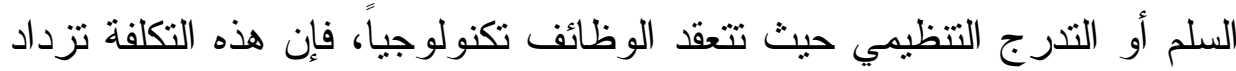

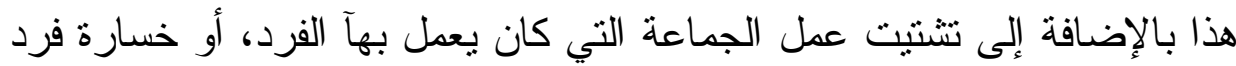

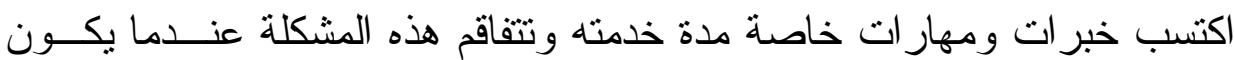
ترك العطل من قبل الأفر اد المتميزين في أدائهم. (Oliver R, E, 2008: 50)

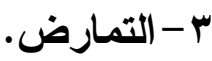
يعتبر التمارض الوسيلة الأكثر شيوعا بين العاملين غير الر اضـين عـن

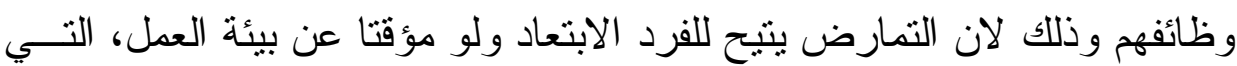
يسبب وجوده بهاً إلى الثنعور بالاسنياء و التضايق. ويمكن تحديد الأفر اد الذين يلجئون إلى التمارض مــن خــلال ســلات الحضور وملفات الموظفين ، حيث أنها إذا تجاوزت العدد الطييعي ، فإنها تثبير

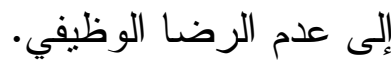


ع - كثرة الشكاوى.

تؤكد الدر اسـات أن الثكاوى مؤشر مهم لمعرفة الرضـــا الـــوظيفي فـي المنظمة وذلك من خلال حصر كل الثكاوى المقدمة في فترة معينة وتـــنيفها حسب العو امل المرتبطة بهآ ودر استها للوقوف على الأسباب التي تــؤثز علـى

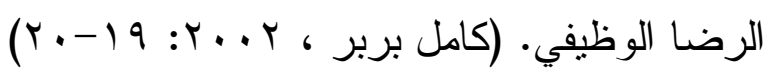

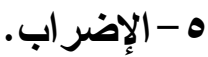

يعتبر الإضر اب من أهم و أكثر مظـــاهر التــذهر وعــدم الرضــــا عــن

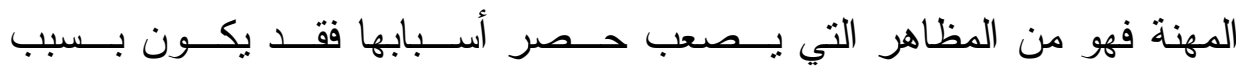
طبيعة العمل في حد ذاته وقد يعود ألي طبيعــة ووضــع الفــرد و الإضـــراب

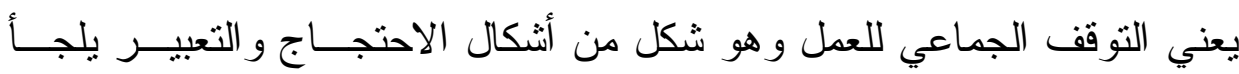
إليها الإفر اد سو اء كانو ا مجموعة صغيرة أو كبيرة لحين حدوث تغيــر ات فــي المكافآت أو ظروف المهنة أو المطالبة ببعض الحقوق التي يرونها مضمونة وقد

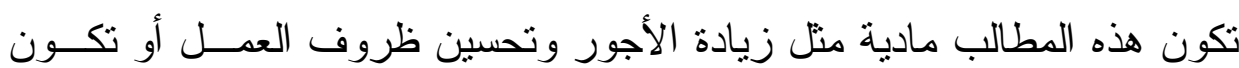
معنوية.

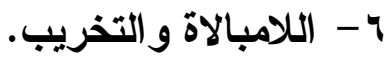

يثاهد تخريب أجززة وهياكل المؤسسات ،أو الثركات في المنظمات التي يشعر عمالها بعدم الرضا، وذلك أن العامل المنسجم مع أهداف المنظمة يـسعي دائما للحفاظ علي تجهيز ات ووسائل العمل ، الذي هـــو بالنـسبة لــه مــصدر الإحساس بالسعادة في حياته المهنية. 
ويسللك العامل سلوك اللامبالاة عندما لا تمنل له الوظيفة أي شيء بستحق

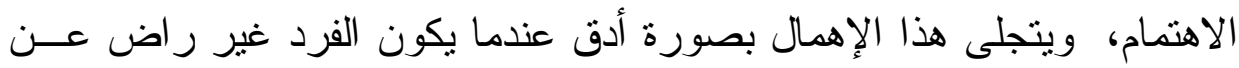

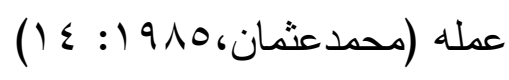

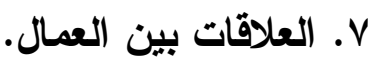

تمكنتا طبيعة العلاقات بين العمال من معرفـــة الرضــــا الــوظيفي مــن

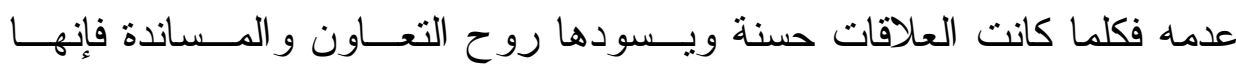

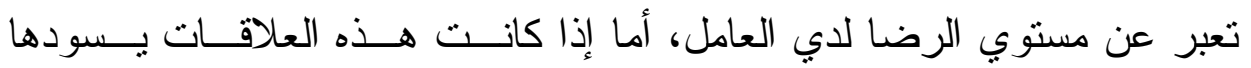

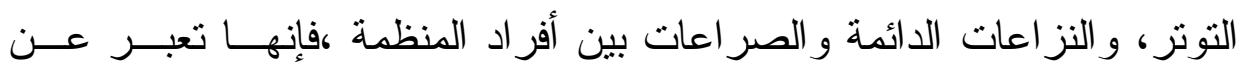

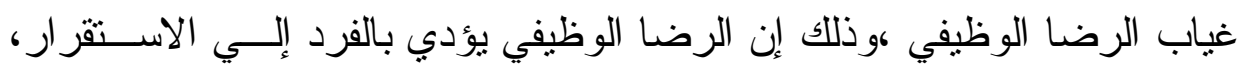

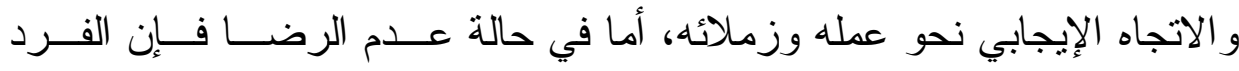

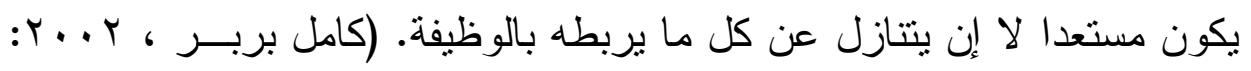




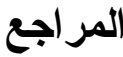

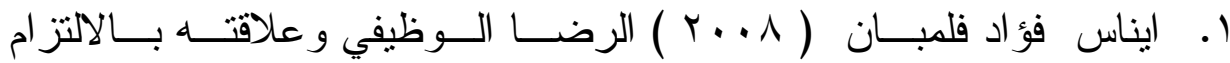
التتظيمي لدى المشرفين التربويين و المشرفات التربويات بـإدارة التربيــة و التعليم ، بمدينة مكة المكرمة ، جامعة ام القرى ، رسالة ماجستير غيـر

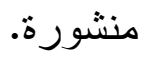

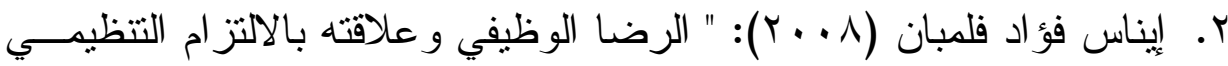

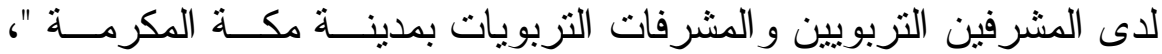
رسالة ماجستير ، جامعة أم القرى.

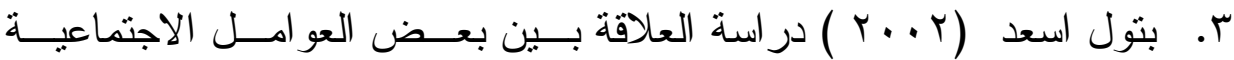

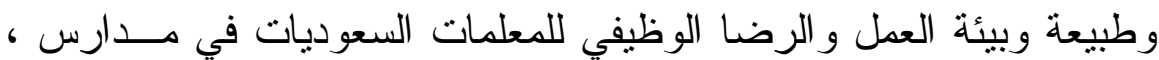
المرحلة الثانوية في مدينة جدة- رسالة ماجستير غيــر منـشورة - كليــة

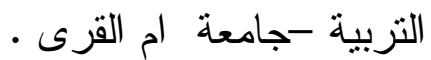

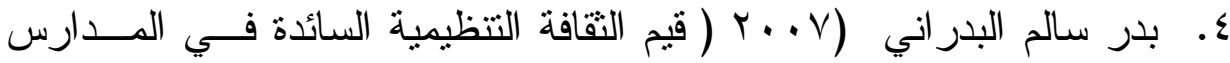
الثانوية للبنين في المدينة المنورة وعلاقتها بالرضا الوظيفي للمعلمين مسن الثن وجهة نظر هم ، رسالة ماجستير غيـر منسشورة قـسم الادارة التربويــة فيسة و التخطيط ، كلية التربية ، جامعة ام القرى مكة المكرمة.

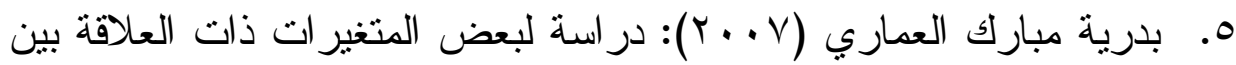
الرضا الوظيفي العام و الو لاء التتظيمي لاى عضوات هيئة التنريس بجامعة

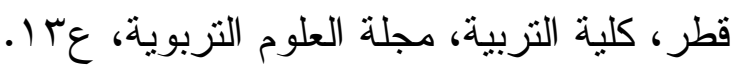

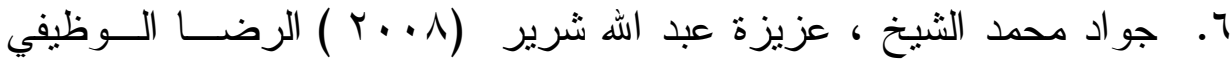

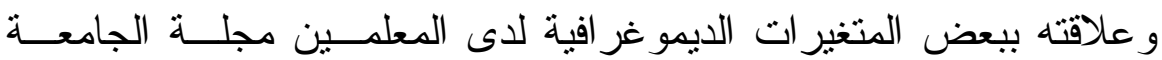


الإسلامية سلسلة الدراسات الانسانية كلية الثربية ، فلسطين العسد ( )

$$
\text { المجلد (17 ) (1 ). }
$$

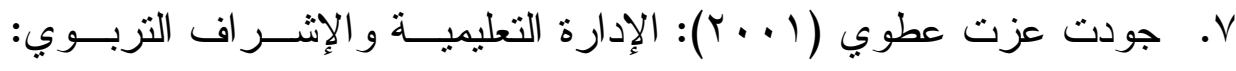
أصولها وتطبيقاته، الدار العلمية الدولية، عمان، الأردن.

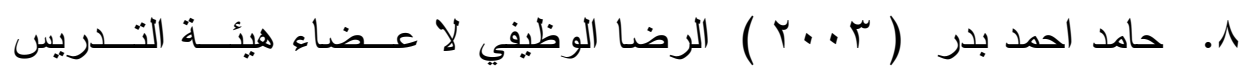

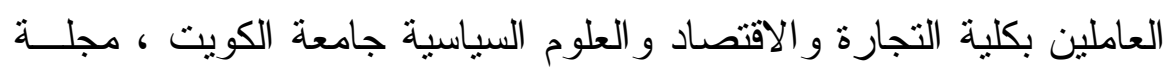

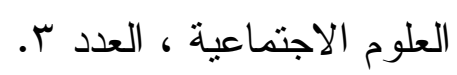

9. حامد محمد زهران (1990 ) دراسة العلاقة بن جوانب الصحة النفسية و الرضا المهني لاى طلاب وخرجي شعبة التعليم الابتدائي بكلية التربية-

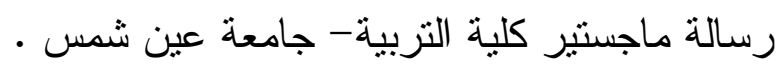

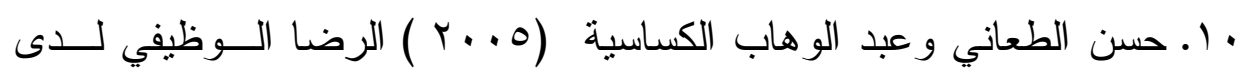

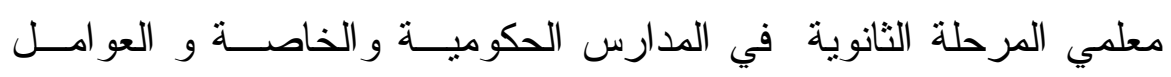
المؤثرة فيها في محافظة العاصمة - الأردن.

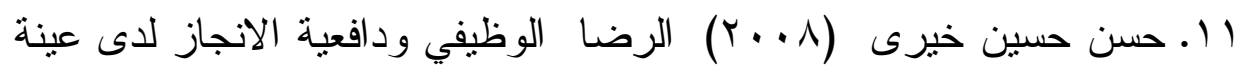

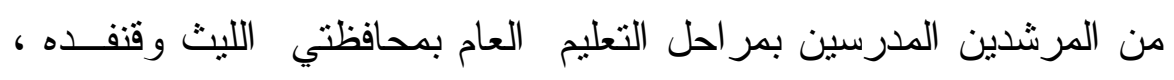

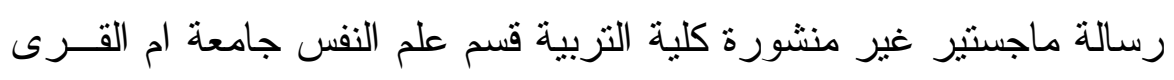

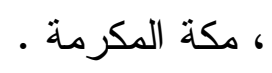

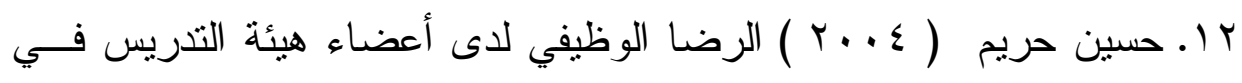

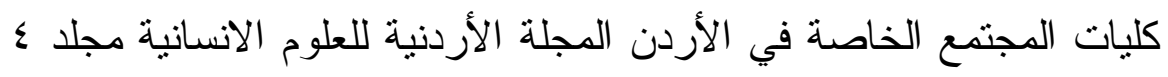

$$
\text { عدد } 0 .
$$

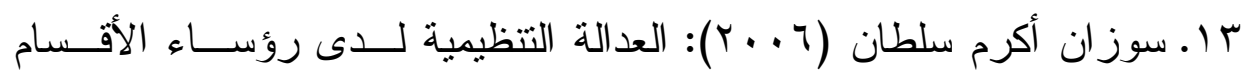

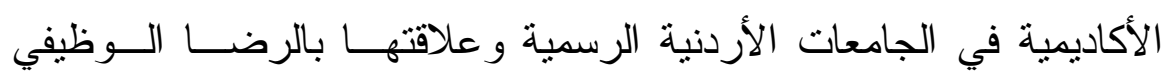


و الو لاء التنظيمي لأعضاء الهيئات التندريسية فيها، أطروحة دكتور اه غيـر منشورة، جامعة عمان العربية للار اسات العليا، عمان، الأردن.

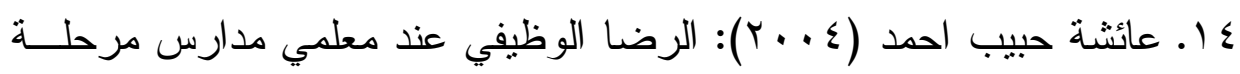
التعليم الأساسي بمدينة سبها ،رسالة ماجستير غير منشورة ،جامعة سبها.

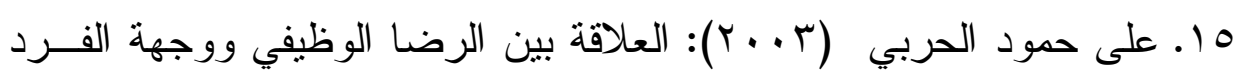

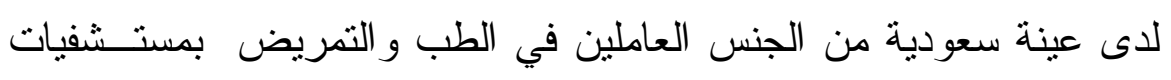

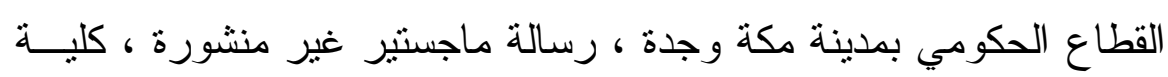
التربية قسم علم النفس، جامعة ام القرى.

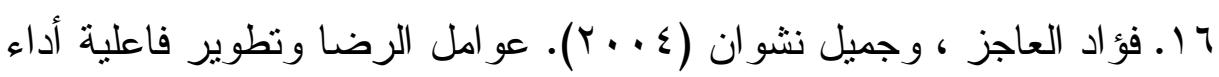

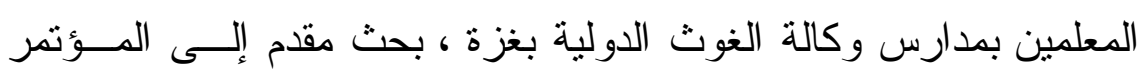

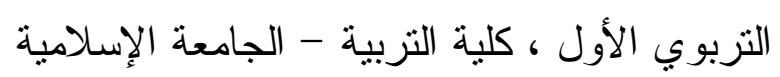

